\title{
Xamãs e xamanismos: reflexões autobiográficas e intertextuais sobre a antropologia $^{1}$
}

\author{
Esther Jean Langdon \\ Universidade Federal de Santa Catarina, Florianópolis, Brasil \\ E-mail: estherjeanbr@gmail.com
}




\section{Resumo}

O trabalho é uma reflexão autobiográfica sobre a adequação dos modelos antropológicos para o estudo das práticas xamânicas no Sul da Colômbia durante um período de quarenta anos. Meu paradigma inicial para o estudo do xamanismo partiu da tradição histórico-cultural da antropologia norteamericana de Boas até Geertz, na qual o xamanismo é visto como um sistema cultural que se transforma ao longo da história e do espaço. Dada a ausência de xamãs Siona praticantes durante os anos 1970, uma parte da minha tese de doutorado tratou da reconstrução do que pode ser considerada a tradição Siona do xamanismo, como expressada pelas narrativas e pelos mitos contados por aqueles que haviam recebido o treinamento xamânico. Neste trabalho, examino a reemergência dos xamãs Siona, enfocando a vida e a personalidade de seu xamã contemporâneo mais conhecido, e avalio a multiplicidade de fatores que têm contribuído para esse ressurgimento e sua expressão, tanto na região quanto na cena global.

Palavras-chave: Xamanismo. Xamãs contemporâneos. Reflexividade. Subjetividade. Intertextualidade.
Abstract

This paper is an autobiographical reflection on the adequacy of anthropological models for the study of shamanic practices in Southern Colombia over the period of forty years. My initial paradigm for understanding shamanism was based on the North American cultural historical tradition from Boas to Geertz, in which shamanism is seen as a cultural system that transforms through history and space. Given the absence of practicing Siona shamans in the 1970's, part of my doctorate concentrated on the reconstruction of what can be considered traditional Siona shamanism as expressed by narratives and myths told by those who had trained as shamanic apprentices. In this paper I examine the resurgence of Siona shamans, focusing upon the life and character of the most well known contemporary shaman and assess the multiplicity of factors that have contributed to this resurgence and its expression in the region as well as on the global scene.

Keywords: Shamanism. Contemporary shamans. Reflexivity. Intertextuality. Subjectivity. 
$\mathrm{E}$ ste texto foi inspirado por um convite para participar de um seminário com um título enigmático: Dilemas xamânicos da modernidade. Quando sentei para escrever minha apresentação, fui forçada a perguntar-me: são os xamãs que estão perplexos com a modernidade ou somos nós, antropólogos, que estamos perplexos com a pluralidade de xamanismos que se manifestam hoje em dia? Desde minha iniciação na antropologia americana, há mais de quarenta anos, a multiplicidade de vozes falando sobre o xamanismo ou reivindicando o título de xamã cresceu com tamanha intensidade que poderíamos nos questionar sobre a utilidade conceitual dos termos "xamã" e "xamanismo", tendo em vista o processo de globalização.

Certamente não era esse o caso nos anos 1960, quando os estudos sobre o xamanismo, um foco da curiosidade antropológica desde o início da disciplina, estavam passando por um novo boom. Lembro-me da comoção e do interesse despertados pelo tema na Reunião da Associação Antropológica Americana de 1968. Todos estavam falando sobre o primeiro livro de Carlos Castaneda (1968) que tinha acabado de ser publicado. O simpósio sobre xamanismo e alucinógenos foi recebido com um auditório lotado no qual Michael Harner argumentou que as práticas de bruxaria da Idade Média e do Renascimento não eram uma ficção, mas uma realidade ligada a voos xamânicos causados por unções psicotrópicas aplicadas a tecidos vaginais através de cabos de vassoura (Harner, 1973). ${ }^{2}$ Seguindo a definição clássica de Eliade e a escola histórico-cultural de Boas, xamãs e xamanismos eram facilmente identificados. Com origem na Sibéria, essa religião arcaica difundiu-se através das culturas do Círculo Ártico, assim como daquelas do Novo Mundo. ${ }^{3}$ 
Eu compartilhava essa noção do xamanismo como um fenômeno histórico-cultural com fronteiras claras que tinha persistido e mudado ao longo do tempo. Muito influenciada pela noção de Geertz (1966) da cultura como um sistema simbólico, enfatizava o aspecto coletivo do xamanismo como um sistema cosmológico no qual os xamãs desempenham papéis específicos, dependendo do contexto histórico e cultural (Langdon, 1991a, 1991b). A tarefa da antropologia era documentar as variedades do xamanismo em seus contextos culturais e históricos particulares, e eu editei dois livros sobre xamanismo com o objetivo de apresentar as dinâmicas desse fenômeno em diferentes contextos etnográficos (Langdon, 1992, 1996). Em um deles, Brunelli (1996) argumenta que pode existir uma situação de xamanismo sem xamãs, enfatizando a persistência das visões coletivas sem a presença de xamãs praticantes.

O enfoque no xamã, e não no xamanismo, também faz parte do interesse antropológico há muito tempo. As primeiras discussões sobre o tema incluíram debates sobre a estabilidade mental dos xamãs, e alguns argumentaram que esses manifestam personalidades psicóticas em contextos culturais nos quais esse desvio é desenvolvido como um papel positivo. Hoje em dia, em geral o xamã é tratado como possuindo poderes especiais que lhe possibilitam ser um mediador entre diferentes mundos (Carneiro da Cunha, 1998). Uma forma extrema do xamã individual é encontrada no discurso da Nova Era, que reúne o xamã como possuidor de poderes não usuais com uma espiritualidade primordial e universal e estados alterados de consciência (Hamayon, 2001). Em todas as partes do mundo, são conduzidos workshops xamânicos que treinam as pessoas para se tornarem xamãs através de estados alterados de consciência. Esses novos xamãs refletem a ideologia moderna do individualismo (Dumont, 1986), em contraste com a noção de pessoa proposta por Mauss, que foi revitalizada em discussões sobre a construção do corpo na Amazônia (Langdon, 1995; Seeger, Da Matta e Viveiros de Castro, 1987).

Da mesma maneira como pessoas ligadas ao universo da Nova Era apropriam-se das práticas xamânicas, os xamãs nativos se mostram igualmente capazes de se apropriarem de uma grande variedade de tradições 
culturais, incluindo a biomedicina (Dobkin de Rios, 1992; Greene, 1998; Luna e Amaringo, 1991); além disso, os xamãs misturam-se com imagens hegemônicas sobre os poderes mágicos nativos para se tornarem parte da rede de alternativas de feitiçaria e cura híbrida externa às comunidades indígenas (Joralemon, 1986; Ramírez de Jara e Pinzón Castaño, 1992; Taussig, 1987; Vidal, 2002; Whitehead, 2002). Alguns são modernos o suficiente para navegar nos círculos neoxamânicos globalizados (Joralemon, 1990; Joralemon e Sharon, 1993).

Minha proposta aqui não é desenvolver uma dicotomia entre xamãs tradicionais e modernos ou um paradigma único capaz de abranger a pluralidade de xamãs e xamanismos. Refletindo sobre meus quarenta anos de estudos sobre o xamanismo, argumento que, para uma compreensão adequada do xamanismo, assim como de qualquer outro fenômeno social, é necessário abandonar o conceito de cultura como uma unidade holística com fronteiras claras e espaço delimitado. Além disso, nossas monografias precisam deixar de lado a voz monofônica e autoritária para retratar a multiplicidade dos fenômenos xamânicos, nos quais existem pouca unidade, muita fragmentação e fronteiras imprecisas (Gupta e Ferguson, 2001). De fato, com relação à região onde fiz minha pesquisa de campo, no Putumayo, Sul da Colômbia, isso já foi feito com sucesso. Michael Taussig (1987) descreve de maneira inovadora as práticas mágicas e xamânicas espelhadas nas imagens hegemônicas dos indígenas. Seu uso criativo da intertextualidade faz com que seu livro possivelmente seja a primeira etnografia verdadeiramente pós-moderna. Ele cita meu trabalho em algumas passagens, descrevendo minha tese de doutorado como um relato do "tipo ideal" da cosmologia Siona (Taussig, 1987, p. 263).

Trinta e quatro anos se passaram desde que terminei minha pesquisa de doutorado entre os Siona. Desde então, eu os visitei quatro vezes: em 1980, em 1985 e duas vezes em 1992. Quando fui embora em 1974, os Siona estavam lamentando a falta de um verdadeiro mestre xamã (cacique-curaca) que poderia protegê-los e manter a saúde e o bem-estar geral. Desde então, tem havido um ressurgimento da prática de rituais xamânicos pelos Siona. Refletindo sobre 
a emergência desses xamãs Siona, que têm se tornado visíveis num cenário regional e nacional a partir do fim dos anos 1980, pretendo dialogar com minhas raízes na antropologia americana e as mudanças em enfoques e teorias que somos forçados a fazer com os desdobramentos históricos. O estudo do xamanismo é extremamente frutífero para revelar as inadequações e as limitações da antropologia (e aquelas dos antropólogos) e confirma que essa não é uma ciência que faz previsões, mas sim um campo intelectual que precisa se transformar para acompanhar os processos de globalização.

Minha decisão de estudar os índios Siona da Floresta Amazônica na minha pesquisa de doutorado foi resultado de uma curta experiência de campo com os curacas do Alto Sibundoy, nome regional emprestado da língua quéchua que é usado para designar os especialistas em cura ritual que nós, os antropólogos, denominamos como xamãs. Quando cheguei à Colômbia, antes de começar meu trabalho de campo no Vale de Sibundoy, encontrei alguns curacas em um mercado no Vale Cauca, onde estavam vendendo ervas medicinais e produtos exóticos da floresta, tais como a pata do tapir e outros objetos conhecidos pelo seu poder no sistema de medicina popular colombiana. Entre seus produtos à venda, podiam ser encontradas garrafas velhas de aguardiente cheias de yajé, ${ }^{4}$ uma bebida alucinógena usada na região do Putumayo em rituais de cura. Vestidos em suas ruanas listradas tradicionais e usando feixes longos e pesados de contas, esses xamãs comerciantes se destacaram nos mercados locais, e um amigo colombiano me informou que eles migraram do seu vale, no Sul da Colômbia, para as principais cidades do país e que alguns chegavam a viajar até a Venezuela.

Durante o tempo que passei no Vale, visitei vários curacas e participei de suas cerimônias de cura, nas quais curavam indígenas assim como visitantes não indígenas que tinham ido para o Vale atrás de seus serviços. Eles me indicaram que sua fonte de yajé e treinamento e conhecimento xamânico procedia dos mestres xamãs do baixo Putumayo, e para mim se tornou claro que uma antiga rede xamânica operava desde antes da Conquista, cuja origem estava nas florestas e através da qual as práticas e os produtos xamânicos eram 
levados para a região andina (Langdon, 1981). Essa rede envolvia a troca de artefatos e saberes rituais. Após passar longos períodos de aprendizado nas terras baixas, os Sibundoy traziam de volta misturas prontas de yajé, pedaços do cipó com o qual esse é feito, plantas medicinais e objetos rituais. A aquisição de conhecimento xamânico, conhecido como pinta ou visões e associado com canções e espíritos específicos, era igualmente importante nessas viagens. O conhecimento e a capacidade do xamã para viajar por diferentes domínios do universo, os espíritos que ele conhece e a pinta que ele domina são únicos, baseados em suas experiências pessoais e nas experiências de beber yajé com outros xamãs. Para aumentar seu poder, os xamãs estão sempre visitando uns aos outros para aprender sua pinta. Essa região é caracterizada por uma cosmologia xamânica que compartilha elementos comuns, mas as práticas rituais dos diferentes grupos étnicos resultam da diversidade de tradições e conhecimentos (Langdon 1979a). Curiosa para estudar as raízes do xamanismo Sibundoy nas terras baixas, encontrei-me brevemente com Scott Robinson, que estava terminando sua pesquisa de doutorado entre os Kofan na selva amazônica de Equador (Robinson, 1996). Ele me estimulou a procurar os Siona, localizados na região do Rio Putumayo, que divide a Colômbia e o Equador, indicando que eles pareciam ocidentalizados em sua cultura material, mas que ainda retinham muito conhecimento xamânico.

Os Siona foram um grande grupo espalhado pela região do baixo Rio Putumayo e seus tributários antes da chegada dos europeus, mas em 1970 restavam aproximadamente 250 pessoas, das quais a metade morava na pequena reserva indígena de Buenavista, com o resto espalhado ao longo do rio em pequenos aldeamentos entre os colonos, que começaram a migrar para a região em números crescentes a partir da década de 1960. Os europeus tiveram uma presença intermitente na região desde o século XVII, mas a primeira missão permanente foi estabelecida com sucesso apenas no início do século $\mathrm{XX}$, quando os Siona passaram a ter contato contínuo com a sociedade envolvente. Essa missão tentou converter os indígenas e forçou as crianças a entrarem no seu internado, o que resultou na dissemi- 
nação de epidemias que reduziram $75 \%$ da população Siona em menos de 25 anos.

O escritor beatnik William Burroughs visitou Puerto Assis, no Rio Putumayo, em 1953, em sua viagem psiconáutica em busca de experiências com o yajé, nome regional para ayahuasca. A estrada que partia de Pasto nas terras altas ainda não tinha chegado a Puerto Assis, e sua carta para Alan Ginsberg descreve o local como um típico porto ribeirinho, com uma rua de terra na beira do rio, algumas lojas, uma cantina, uma missão e um hotel (Burroughs e Ginsberg, 1963). Para Burroughs, a região estava degenerada e morrendo, e ele era cético com relação aos rumores otimistas de que a exploração de petróleo logo seria desenvolvida ali. De fato, dentro de uma década, a estrada que ligava a esse pequeno centro portuário as terras altas logo foi concluída, facilitando a exploração do petróleo e a migração de milhares de fazendeiros rurais impelidos pela falta de terra nas montanhas. A região florestal, que, salvo à época da borracha, tinha pouca importância, tornou-se economicamente importante. No período em que cheguei lá, em 1970, essa cidade ribeirinha era um centro comercial agitado com cerca de cinco mil habitantes. A população continuou a crescer, e em 1980 um comerciante local me contou que o município já contava com sessenta mil habitantes.

Embarquei em uma grande canoa de carga, do tipo descrito por Burroughs nos anos 1950, para fazer a viagem de $45 \mathrm{~km}$ descendo o rio em direção à reserva indígena. Naquela época, as casas de madeira dos fazendeiros colonos ficavam em meio à floresta ao longo dos bancos do rio e da reserva indígena, apontada pelos passageiros da canoa; era difícil de distinguir dos assentamentos dos colonos. Fui deixada num "puerto" de rio, local de desembarque com degraus de terra que subiam a barranca do rio na direção da casa de Alva Wheeler, o missionário do Summer Institute of Linguistics (SIL) que trabalhava com a comunidade periodicamente desde os anos 1960 (Wheeler, 1967, 1970). Vários indígenas, vestidos com roupa campesina, esperavam no alto da barranca, curiosos para ver quem estava desembarcando. Lembrei-me do conselho de Robinson, que tinha me informado de que, apesar de sua aparência mestiça, cultu- 
ra material e habilidade no espanhol, "eles são indígenas no seu pensamento". Dois anos depois, Andrew Weil, aluno do etnobotânico Richard Schultes e autor do The Natural Mind (1972), visitou a reserva procurando xamãs. Ele ignorou meus comentários similares, julgando que os Siona não tinham mais conhecimentos botânicos ou xamânicos importantes, e foi embora algumas horas depois de ter chegado.

Ali na casa de Wheeler entre os Siona "ocidentalizados", tive uma surpresa prazerosa quando um "verdadeiro" índio entrou vestindo uma túnica (cusma) tradicional com feixes de pequenas miçangas de vidro cobrindo seu pescoço e penas de arara-vermelha nas orelhas. Seu colar xamânico de dezenas de caninos de onça e desenhos delicados pintados no seu rosto completaram as minhas expectativas sobre a imagem do índio autêntico. Uma foto de Ricardo executando uma reza de cura pode ser encontrada na capa de meu livro Portals of Power (1992). Minhas primeiras reflexões sobre o uso da vestimenta contemporânea como resultado da percepção de mudanças nas fontes de poder foram publicadas em 1979 (Langdon, 1979b).

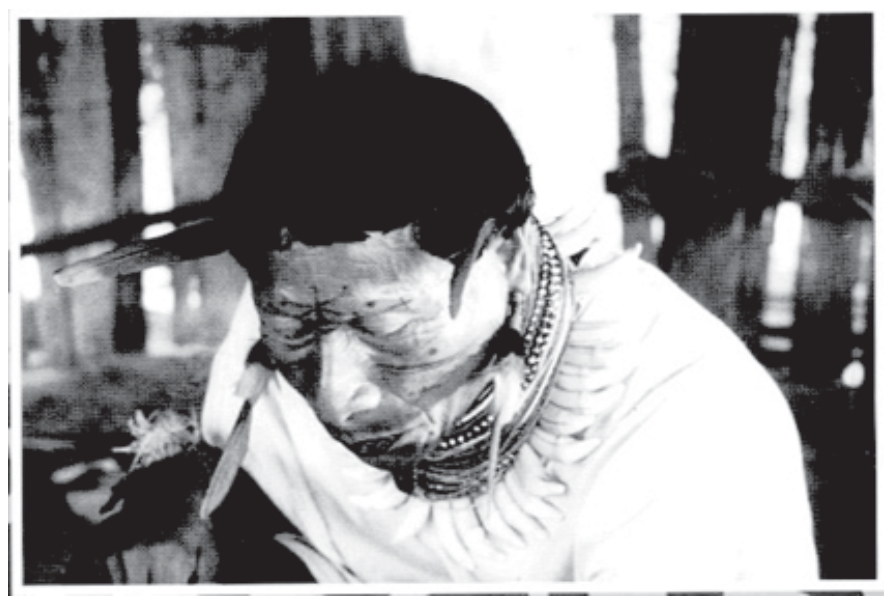

Figura 1: " Ricardo realizando uma cura Fonte: Carlos Garibello Aldana.

Ricardo, uma das poucas pessoas mais velhas que continuavam a usar a vestimenta tradicional, ${ }^{5}$ tornou-se meu colaborador-chave durante os dois anos e meio seguintes. Filho de um xamã Siona co- 
nhecido, Leonides, e irmão de Arsênio, considerado o último mestre xamã Siona, Ricardo passava horas narrando viagens xamânicas, batalhas entre os xamãs Siona e os missionários espanhóis e o desaparecimento das comunidades Siona no século XX devido às lutas xamânicas (Langdon, 1990). Durante esses anos, aprendi o suficiente da língua para gravar, traduzir e discutir mais de cem narrativas que foram contadas por ele e outros velhos que tinham sido aprendizes de xamãs. Inspirada pela ideia de Geertz da descrição densa e por sua teoria da religião como um sistema cultural, sugeri que essas narrativas, que frequentemente eram contadas para interpretar eventos de enfermidade grave, tinham um papel análogo ao do ritual, fornecendo um "modelo de" e um "modelo para" a cosmologia Siona que é constituída por dois lados da realidade, a realidade ordinária da vida cotidiana e a realidade invisível, que está por trás do que normalmente vemos. As narrativas tinham um papel na organização da práxis da busca de cura nos casos de enfermidade grave (Langdon, 2001). Somado a isso, as narrativas que enfocavam especificamente as visitas xamânicas aos outros domínios do universo me ajudaram a caracterizar a especificidade do sistema cosmológico Siona e de sua experiência ritual (Langdon, 1979a).

Apesar do fato de Ricardo ter conhecimento e experiência extensivos no treinamento xamânico e, como outros velhos, ter realizado rituais de cura para doença menores, ele não tinha atingido o nível de mestre xamã. Quando seu irmão Arsênio morreu nos anos 1960, a comunidade esperava que Ricardo tomasse seu lugar. Os homens possuindo poder xamânico se reuniram após a morte para tomar yajé. Segundo Wheeler, que estava na comunidade na época, todos sofreram experiências assustadoras, inclusive Ricardo. Nos meus diálogos com Ricardo, ele explicou que havia sido arrastado para a escuridão, o reino dos wati. Devido a repetidos ataques de feitiçaria causados por outros xamãs durante sua vida, seus poderes estavam danificados, deixando-o incapaz de desempenhar o papel de cacique-curaca, o líder xamânico que guia a comunidade nos rituais de yajé e faz as mediações com os mestres dos animais e outros seres invisíveis para obter sucesso nas caças e colheitas, proteger dos ataques de feitiçaria e curar. 
Durante minha estada entre os Siona até 1974, a situação era de xamanismo sem xamãs. Os Siona não tinham xamãs conduzindo os rituais de yajé, e todos lamentavam a perda da mediação protetora com os seres do lado invisível da realidade. Na sua ausência, as enfermidades sérias e a morte continuavam a ser atribuídas às ações de práticas de feitiçaria e aos wati invisíveis. Quando necessário, eles procuravam xamãs de outros grupos para realizar rituais de cura. No início de minha pesquisa de campo, Salvador Moreno, um xamã mestiço, foi chamado para encontrar uma criança perdida na floresta. Eu não fui convidada para esse ritual de yajé, que não obteve sucesso. Salvador disse que os espíritos tinham levado a criança para muito longe no reino dos wati, de maneira que era impossível trazêla de volta. Ricardo, que participou do ritual, me contou que só viu escuridão e que seus ouvidos ficaram cheios com o barulhento zumbido das cigarras. Ele acusou Salvador de enfeitiçá-lo. A família de Ricardo também culpou Salvador pela morte de uma menina de seis anos de idade que ocorreu pouco depois disso.

Ricardo, porém, não é o sujeito dessa narrativa. Ele foi o centro da minha tese de doutorado, e eu analisei certos aspectos de sua carreira xamânica e de nosso relacionamento em outros trabalhos (Langdon 1999, 2002, 2004). Aqui quero refletir sobre outro Siona que conheci, Pacho (Francisco) Piaguaje, casado com uma filha de Arsênio. A mãe de Pacho, a segunda mulher de Arsênio, era a Siona mais velha da comunidade e morava com sua família. Pacho era aliado a um grupo de famílias que, em certas situações, se opunha àquele associado com Ricardo. Para localizá-lo nos trabalhos antropológicos, ele é parente de Salvador Moreno, tornado conhecido para eles através de Michael Taussig (1987). De fato, Taussig viajou para o Putumayo pela primeira vez comigo depois que lhe contei sobre a rede xamânica de xamãs indígenas e mestiços entre o Vale Sibundoy e as terras baixas.

Pacho tinha cerca de cinquenta anos nessa época e, diferente da geração de Ricardo - uns vinte anos mais velha -, tinha abandonado o treinamento xamânico quando era novo por não ser capaz de manter as restrições alimentares e sexuais necessárias. Alistou-se com 
outros Siona na Marinha no conflito entre a Colômbia e o Peru nos anos 1930. Contou-me que gostou da experiência e que bebeu pólvora com aguardiente para espantar seus medos. Na ocasião, não percebi o significado dessa mistura como uma evidência da construção do corpo e da consubstancialidade amazônica.

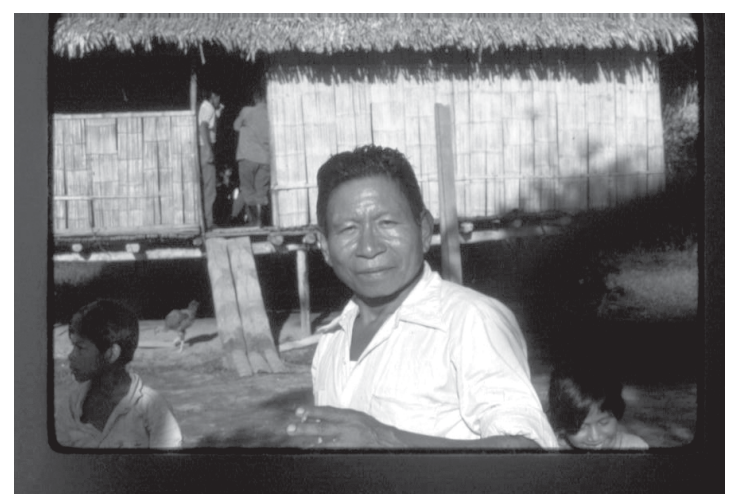

Figura 2: “ Pacho em 1971

Fonte: Esther Jean Langdon.

Talvez tenha sido sua experiência na Marinha ou simplesmente sua astúcia e adaptabilidade que o tornaram capaz de estabelecer contatos frequentes e proveitosos com não indígenas. Nos anos 1970, formou parcerias com colonos num acordo que chamavam "as médias". Ele plantava sementes de arroz financiadas pelo seu parceiro não indígena e dividia as colheitas e os lucros com ele. Também era guia para os caçadores esportivos não indígenas, que ficavam em sua casa enquanto visitavam a Floresta Amazônica. Durante o período em que o conheci melhor, ele foi eleito como gobernador, uma posição criada pelo governo colombiano para fazer a mediação entre a comunidade indígena e os programas governamentais. Ele recebia um salário para ocupar essa posição, aumentando sua aquisição de bens manufaturados, assim como suas viagens para fora da reserva. Ricardo e seus parentes o acusavam de beber muita aguardiente, a cachaça colombiana que era proibida para os xamãs Siona. Ouvi muita fofoca sobre como se tornara um bêbado ridículo quando viajava a Puerto Assis e outras desventuras ligadas ao seu abuso do álcool. 
Pacho, assim como toda sua família, tinha um bom domínio do espanhol, e vários de seus seis filhos casaram-se com não indígenas. Eu era comadre de um de seus filhos, e outros dois, Felinto e Pacheco, colaboraram comigo ao longo dos anos. Quando Felinto era jovem nos anos 1960, passou alguns meses em Bogotá trabalhando com Manrique Casas, um linguista colombiano. Também nesse período serviu como importante informante para Maria Rosa e José Recasens, antropólogos que estavam vinculados ao Instituto Colombiano de Antropologia (Mallol de Recansens, 1963; Mallol de Recasens e Recansens, 1964/1965). Casas o ensinou a escrever na língua Siona, e, quando voltou para Buenavista, ele registrou várias narrativas contadas pelos mais velhos e, generosamente, as compartilhou comigo durante minha pesquisa de campo. Pacheco era um dos filhos mais novos de Pacho. O mais educado dos irmãos, ele tornou-se professor e durante os anos 1980 trabalhou para Alva Wheeler, ajudando-a a traduzir e mimeografar partes da Bíblia para os Siona.

Pacho tinha um senso de humor excelente e sempre foi altamente simpático nas conversas durante nossos frequentes encontros. Contudo, eu não levava suas discussões sobre o conhecimento tradicional xamânico muito a sério, em parte porque era influenciada pela opinião de Ricardo de que ele bebia demais e sabia pouco sobre o que significava ser um xamã. Uma vez repeti para Ricardo o que Pacho havia me contado sobre as práticas xamânicas; Ricardo riu e perguntou quem tinha me ensinado tais besteiras. Suspeito que o outro motivo pelo qual eliminei Pacho como um colaborador sério para meus interesses xamânicos era minha abordagem normativa do estudo da cultura. Eu o identificava como um "cultural broker" ou mediador, devido às suas atividades com não indígenas. Embora eu conhecesse vários comerciantes e colonos na área e interagisse com eles, havia sido o conhecimento da rede xamânica entre os índios e os mestiços que me estimulara a estudar os Siona, minha visão antropológica era restrita e na prática estava virtualmente contida dentro dos limites da Terra Indígena, com enfoque muito menor nas redes que os Siona criavam fora dela e nas relações entre as forças locais, regionais e globais. Naquele tempo, cultura e espaço formavam uma unidade para mim. 
Contrariando minha visão de Pacho como o índio mais aculturado de sua geração, ele me surpreendeu em 1973 numa mutirão, ou minga, que organizou como governador para limpar o pátio escolar. Como de costume, as mulheres haviam preparado chicha e comida, e, depois de terminar a limpeza do pátio, estávamos sentados na varanda da escola comendo e bebendo. Pacho estava um tanto embriagado e fez um longo discurso sobre a necessidade de manter os antigos costumes e a língua Siona. Em certo momento, me elogiou dizendo que eu estava ali para aprender as práticas tradicionais e a língua que estavam sendo abandonadas pela maioria das pessoas. Quando terminou esse longo monólogo pronunciado inteiramente em espanhol, começou a chorar. Naquele tempo, minha interpretação foi de que ele estava chorando porque era um dos pioneiros em dar as boas-vindas para as práticas e a língua não indígenas e deixar suas práticas tradicionais atrás.

A disposição e a facilidade de Pacho para interagir com os colonos mais que os outros de sua geração, bem como sua adaptabilidade para contextos não indígenas, contrastavam ainda mais com o medo e a reserva que Ricardo demonstrava diante dos não indígenas. Ricardo percebia os colonos como poluídos e perigosos para seu poder xamânico. Para ele, eles ameaçavam seu corpo de xamã por não observar certas prescrições higiênicas ligadas à menstruação e ao nascimento (Langdon, 1995). Ricardo foi testemunha e sobrevivente da violência sofrida por sua geração, quando criança durante os primeiros 25 anos do século XX. Lembranças dessa violência ainda estavam presentes nos sonhos que ele me contava. Pacho, por ser vinte anos mais novo, foi, talvez, poupado do impacto desses anos.

Para um xamã, o sangue menstrual é extremamente perigoso, pois seu odor pode levar as entidades invisíveis a destruírem a substância xamânica que se acumula dentro de seu corpo e que representa seu conhecimento. As mulheres Siona menstruadas, portanto, devem praticar a reclusão. Tanto o pai quanto a mãe de uma criança que ainda não nasceu devem manter uma distância dos xamãs e praticar uma couvade conjunta até que a criança chegue aos quatro ou cinco meses. No início da minha pesquisa de campo, eu fui clara- 
mente informada pela nora de Ricardo de que nunca deveria oferecer comida a ele ou visitar sua casa quando estivesse menstruada. Contudo, tais práticas estavam sendo abandonadas por algumas mulheres mais jovens. Em 1980, quando fiz outra visita e Ricardo estava novamente construindo seu conhecimento xamânico, uma jovem mulher grávida entrou em sua casa. Depois que ela foi embora, ele expressou sua frustração dizendo que seus novos esforços para construir poder xamânico eram vãos devido à presença crescente dos colonos na reserva e à falta de respeito com o corpo do xamã demonstrada pelas mulheres mais jovens em estados de poluição. Ele sentia que sua delicada substância xamânica estava em perigo.

Pacho, pelo contrário, expressava sentimentos muito diferentes com relação aos não indígenas e suas práticas. Ele me contou uma história dramática sobre uma enfermidade grave no estômago que tinha sofrido alguns anos antes. Depois de tentar curar-se com xamãs e outros curadores tradicionais durante meses, procurou uma curandera colona que o curou esfregando sangue menstrual em seu corpo. Depois de terminar sua narrativa, ele adicionou: "acredite ou não, mas funcionou". Contrastando com Ricardo, que temia a presença dos não indígenas, bem como a comida preparada por esses, Pacho não tinha problemas em compartilhar comida e alojamento com pessoas de fora ou em viajar para fora da comunidade.

Quando deixei a comunidade Siona em 1974 para defender minha tese de doutorado, previ o desaparecimento da cultura Siona e a tradição xamânica particular a eles, a não ser que aparecesse algum tipo de liderança, talvez carismática, que pudesse revitalizar as práticas xamânicas. Eu não poderia estar mais errada sobre o que e quem reinventaria as práticas xamânicas em Buenavista. Nem poderia ter previsto as vastas mudanças que ocorreriam na região do Putumayo como resultado do tráfico de drogas e da presença do conflito entre as guerrilhas, paramilitares e militares, que se assemelham a uma guerra civil, bem como do surgimento dos movimentos políticos indigenistas que refletem a dinâmica da etnicidade na região.

Quando voltei em 1980 para passar um mês, parecia que minhas previsões estavam tornando-se realidade. Os Siona estavam mais 
dependentes de bens comerciais e, dessa maneira, pareciam mais pobres do que no início dos anos 1970. Além das fofocas normais sobre os vizinhos, das doenças e dos ataques de feitiçaria, novos temas políticos apareceram nas conversas. Um deles foi sobre a visita de dois membros do Conselho Regional Indígena do Cauca (CRIC) que estavam na reserva tentando recrutar participantes para um comício nacional que estava sendo organizado nas terras altas de Cauca. Cinco anos antes, Ricardo, Pacho e dois de seus filhos tinham participado de um evento similar. Ricardo lembrava-se do clima frio nos Andes e dos gritos indignados nas reuniões que o assustavam. CRIC foi um assunto de muitas conversas durante essa viagem; eu ouvia opiniões sobre conflitos de classe, pobreza e comunismo. O filho de quatro anos de minha comadre me acusou de ser rica, porque eu tinha três pares de sapatos.

Embora Ramirez (2002) reporte-se a um movimento indígena crescente nas terras altas do Putumayo nos anos 1980, as políticas ligadas à etnicidade não eram um tema nas minhas discussões com os Siona. A única menção à identidade étnica aconteceu com Pacheco, o filho de Pacho que estava trabalhando para o missionário Wheeler. Eu o visitei quando ele estava tomando conta da casa de Wheeler durante uma longa ausência do proprietário. Pacheco me mostrou o trabalho que estava fazendo e também uma bandeira que havia pintado. Wheeler tinha pedido que criasse uma bandeira para simbolizar a tribo Siona, e, "depois de pensar e pensar", Pacheco decidiu que a melhor maneira de representar a identidade Siona era através do curaca e de suas práticas. Sua bandeira continha várias imagens xamânicas - o challis de cerâmica usado para beber yajé, a anaconda que é a "dona do cipó", a onça, e a trepadeira e as folhas de yajé. Ao ver essa autorrepresentação da identidade Siona, fiquei pensando qual seria a reação do missionário, que tantas vezes tinha pregado para os Siona que seus espíritos e práticas xamânicas eram obras do Diabo.

Outros temas de conversas durante essa viagem tratavam do crescimento do tráfico de cocaína e da violência militar na região. Finalmente, descobri que Pacho e seu irmão Luciano tinham começado a tomar yajé. A família de Ricardo me contou de uma maneira 
um tanto quanto cínica que eles estavam tomando o yajé regularmente e que qualquer um que quisesse podia beber com eles. Luciano havia morrido pouco antes da minha chegada, e sua família ouviu atentamente as fitas de suas narrativas gravadas durante minha pesquisa de campo anterior. Pacheco me contou que Pacho não estava bebendo yajé no momento porque suas duas noras que moravam com ele estavam grávidas. Ambas eram de famílias de colonos.

Passei aquele mês dormindo na casa de Ricardo e trocando narrativas sobre sonhos com ele (Langdon, 1999, 2004). Como ele estava em pleno processo de recuperar seu conhecimento xamânico, muitos de seus sonhos representavam o crescimento de seu poder e confiança como xamã.

Em 1985 voltei novamente à Colômbia. Em Bogotá encontrei Juan Vieco e Margarita Chaves, jovens antropólogos que estavam estudando os efeitos da colonização na região a partir de 1979 (Chaves, 1998). Eles me contaram que agora os Siona estavam plantando coca; Ricardo tinha mudado para o rio abaixo para morar com sua filha mais velha; Pacho estava realizando cerimônias de cura, principalmente para não indígenas; e o tráfico de drogas e a violência, que já eram evidentes na minha visita de 1980, agora marcavam a vida no Putumayo, bem como no restante do país. Quando cheguei a Puerto Assis, Camacho, um comerciante local que tinha anos de interação com muitos de meus amigos Siona e era compadre de alguns deles, contou-me que a maioria dos jovens Siona tinha se juntado com a luta das guerrilhas.

Minha viagem a Buenavista confirmou muitas das observações feitas por Juan e Margarita, embora não as de Camacho. Fiquei na casa de meus compadres durante uma semana, notando que os Siona estavam em melhores condições do que em 1980. Pacho havia liderado uma campanha para obter um gerador movido à gasolina que fornecia eletricidade durante uma parte do dia para as casas perto da escola. Minha comadre me contou que os soldados haviam encorajado o plantio e o processamento de cocaína quando invadiram a reserva perseguindo os guerrilhas que moravam na região atrás de seus limites. Também ouvi que o motivo de o Ricardo sair da comunidade 
com a família de sua filha foi por causa de uma briga em que seu neto embriagado matou seu primo.

Visitei Pacho, que prometeu me servir yajé em minha próxima vinda. Uma de suas noras estava grávida de novo, por isso ele não estava tomando a bebida na ocasião. Ele havia recebido um número considerável de caçadores esportivos das maiores cidades do país. Mostraram-me fotos de um corretor de seguros de Medellin vestido com roupas e acessórios de camping sofisticados. A família de Ricardo continuava a criticar Pacho pelo fato de ele beber muita aguardiente e dizia que até seu filho Felinto ficava envergonhado devido ao comportamento do pai.

Uma semana depois, viajei descendo o rio num barco comercial com dois netos de Ricardo para visitá-lo e sua esposa em El Tablero, perto de Puerto Carmen. Sua nora em Buenavista havia me dito que ele estava novamente realizando rituais de cura, e eu estava ansiosa para conversar com ele a respeito de suas práticas. Embora minha visita de três dias, para ele e a família de sua filha, tenha sido muito prazerosa e eu tenha me sentido muito bem-vinda, Ricardo estava particularmente fechado para qualquer discussão sobre xamanismo, um tópico preferido para nós nos anos anteriores. Como de costume, fofocávamos; ele me contou histórias sobre espíritos que tentaram capturar a esposa de seu neto e sobre o crescimento recente das igrejas pentecostais na região. Batidas militares nas roças de coca e a presença de guerrilhas na região também eram temas. Ricardo explicou que seu filho havia escondido alguns guerrilhas no passado. Os Siona tendiam a proteger os guerrilhas, que os ensinavam a plantar coca e processar cocaína. Eles também eram vistos como menos violentos que os militares e os paramilitares.

No caminho de volta a Buenavista, fui cuidadosamente revistada em Puerto Carmen por um soldado que desempacotou minha mochila e esvaziou meu tubo de pasta de dente procurando cocaína. Rio acima, soldados equatorianos pararam nosso barco, o "Apollo 2", e fomos forçados a desembarcar, deixando a nossa bagagem para ser revistada. Um homem que tinha uma caixa de uísque de contrabando foi detido e impedido de continuar a viagem. Uma mulher afir- 
mou que um soldado havia roubado seu relógio ao revistar sua bolsa. Os passageiros ficaram bravos, acusaram os soldados de parar o barco unicamente para roubar e disseram que os guerrilhas deveriam matá-los todos.

Fiz mais duas viagens curtas ao Putumayo em 1992. A primeira foi depois de uma conferência sobre literatura oral em Pasto, uma cidade localizada na cordilheira andina no Sul da Colômbia. Lá eu tomei yajé com um professor de filosofia que também havia bebido o chá com Pacho e alguns de seus alunos. Um xamã de Sibundoy, Taita Martin, dirigiu nosso ritual. ${ }^{6}$ Depois de beber uma dose de yajé, ofereceu aguardiente para espantar o amargo gosto do yajé. Ele cantou repetitivamente em espanhol durante a noite, "Buena gente, buena gente; buena pinta, buena pinta", no ritmo de sua pichanga de folhas secas. Descobri que os alunos haviam participado de um ritual similar com Pacho alguns meses antes e experimentado a visão Siona, amedrontadora mas tradicional, de enfrentar olho no olho a anaconda. Taita Martin acusou os xamãs das terras baixas de fornecerem "yajé de cobra", enquanto ele oferecia "yajé do céu", que induzia visões mais bonitas.

Minha visita a Buenavista foi curta e triste. Já tinha o conhecimento da morte de Ricardo logo depois da minha última viagem. Nesta viagem sua nora, minha comadre, me explicou que sua morte súbita em 1986 havia sido causada por feitiçaria mandada pelos xamãs inganos para acabar com seus poderes xamânicos. Seu filho, neto de Ricardo, havia sido pego junto com a prima no centro de Puerto Asis, e ambos foram assassinados a sangue frio por militares (ou paramilitares) na periferia da cidade. A exploração de petróleo avançava no lado equatorial do rio e as grandes mudanças ecológicas eram evidentes; doenças estranhas estavam aparecendo entre as crianças. Havia eletricidade em mais casas. No lugar dos finais de tarde silenciosos com conversas e trocas de narrativas, eu assistia à televisão com meus compadres e seus filhos que estava sendo paga em parcelas pela venda de cocaína. O programa preferido era uma novela de Bogotá sobre Drácula. Assisti ao programa com a família num banco de madeira rústico, e, quando havia interferência na recepção, a filha 
mais velha corria para o lado de fora para redirecionar a antena de bambu, seguindo as orientações de nossos gritos de dentro.

Quando mencionei para meus compadres que Pacho tinha estado em Pasto distribuindo yajé, minha comadre fofocou sobre seus atos vergonhosos em Buenavista. Ele havia prejudicado um colono local misturando yajé e aguardiente, e também estava atraindo estranhos demais para a reserva. Entre eles, havia uma mulher americana. Contaram-me que Pacho ameaçou trocar sua esposa por ela; a esposa, em troca, ameaçou matar a mulher. Um casal "holandês" também ficou com ele. O homem e a mulher foram bem recebidos pelos Siona, pois os ensinaram a fazer artesanato, e a mulher tratou alguns Siona com acupuntura. Uma jovem estudante de antropologia de Bogotá também ficou com Pacho por um tempo, mas evidentemente não interagiu com o restante da comunidade, de maneira que eles praticamente não a conheceram. Finalmente, minha comadre mencionou um jornalista gringo que morou por vários meses numa cabana feita de folhas de coqueiro perto da casa de Pacho para beber yajé com ele. Para ela, ele parecia um pouco doido.

Minha visita a Pacho confirmou sua popularidade crescente como xamã. Ele estava preparando yajé para realizar um ritual naquela noite. Havia um xamã Kofan com ele. Pacho me contou sobre suas sessões de cura bem-sucedidas com não indígenas e mencionou um alemão que havia estado lá na semana anterior. Convidoume para participar da sessão naquela noite, mas, como estava indo embora à meia-noite, não tinha como aceitar.

Minha última visita a Buenavista foi em julho daquele ano, depois de ter passado uma semana em Bogotá numa conferência de antropologia. Lá, numa visita ao Instituto Colombiano de Antropologia, encontrei Pacho, que estava acompanhado pela jovem estudante mencionada acima e por Jimmy Weiskopf, o jornalista gringo que minha comadre tinha mencionado. ${ }^{7}$ Pacho ia oferecer uma conferência sobre plantas medicinais e também estava à procura de financiamento para um projeto de um jardim que queria fazer em Buenavista usando seis hectares de terra. Convidou-me para tomar yajé naquela noite, mas novamente fui forçada a recusar o convite, pois ainda estava preparando minha apresentação para o dia seguinte.

\section{ILHA}


Enquanto estava em Bogotá, entrevistei Jimmy, a estudante de antropologia e sua professora, e descobri mais sobre as atividades de Pacho. Aparentemente, Jimmy não era apenas o jornalista gringo, mas também o "holandês" que visitara Pacho com sua esposa. ${ }^{8}$ Ele me contou que havia se separado de sua mulher e mais tarde voltara sozinho para ficar na casa de yajé de Pacho. Descreveu a si mesmo como um ex-hippie que estava tentando curar seus problemas no pulmão e também buscando um guru. ${ }^{9}$ Encontrou em Pacho esse guru e o igualava a um anjo. Ele pressupôs que Pacho sempre havia sido o xamã da comunidade e mostrava que sabia pouco sobre a tradição xamânica Siona. Contou-me que traficantes de drogas participavam das sessões de yajé em Bogotá e que Pacho realizava um tipo de "terapia". Enquanto eu estava no apartamento de Jimmy, Pacho ligou e pediu-me uma carta de recomendação para seu projeto de plantas medicinais.

$\mathrm{O}$ orientador da estudante me contou que sua jovem aluna tinha certas ilusões sobre Pacho e que passara muito tempo bebendo yajé durante sua estada com os Siona. Ela havia sido mandada para estudar plantas ligadas ao parto e apoiara o projeto de Pacho do jardim, ignorante do fato de que não é o xamã o especialista em plantas, mas sim as mulheres da comunidade.

Depois da conferência, viajei para Buenavista. Entre os passageiros da canoa, estavam dois guerrilhas que desembarcaram no porto da escola de Buenavista e adentraram na selva atrás. Um pouco mais abaixo, desembarquei no porto de meu compadre, mas sem a presença do costumeiro grupo aguardando na barranca para me dar as boasvindas. Normalmente, no silêncio da floresta, os Siona têm ouvidos agudos e escutam os barcos que vêm passando de longas distâncias. Quando percebem que uma canoa está vindo para seu porto, correm para a barranca do rio para ver quem está chegando, como foi o caso em 1970 na minha primeira chegada. Dessa vez não havia ninguém, e, quando subi a íngreme barranca do rio até a casa, descobri o porquê. A eletricidade agora estava disponível também durante o dia para acontecimentos importantes. Toda a família e alguns vizinhos estavam assistindo a um jogo de futebol entre a Colômbia e o Egito na televisão. 
Os poucos dias que passei lá foram preenchidos com visitas aos meus antigos amigos e fofocas sobre aqueles que haviam morrido ou ido embora. Como de costume, também houve muitas acusações de feitiçaria relacionadas aos infortúnios que haviam ocorrido durante minha ausência. Descobri que o projeto de plantas medicinais de Pacho era visto como uma empreitada privada motivada pelo seu desejo de ficar rico. Foram feitas as reclamações de costume sobre o fato de ele beber muito aguardiente, e boa parte da comunidade não o reconhecia como seu mestre xamã. Alguns estavam bravos devido ao fato de ele atrair tantos não indígenas para a reserva.

Não consegui mais voltar ao Putumayo. A violência e a guerra civil na região pioraram, e meus colegas colombianos me avisaram de que era muito perigoso para estrangeiros. Alguns colombianos continuaram a fazer pesquisa de campo na região em condições extremamente difíceis. Recebi um livro de German Zuluaga intitulado Encuentro de taitas em la Amazonia colombiana (UMIYAC, 1999) que é muito relevante para minha narrativa. Essa publicação documenta um encontro financiado pela organização Ingano Tanda Chiridu Inganokuna e pela organização não governamental Amazon Conservation Team. Cento e quarenta indígenas, incluindo quarenta taitas (o novo nome para os curacas na região ${ }^{10}$ ), se reuniram para formar a Unión de Médicos Indígenas Yageceros de la Amazonía Colombiana (UMIYAC), dedicada a recuperar a tradição xamânica e a ecologia da região.

Sete grupos indígenas participaram desse encontro: Siona, Kofan, Ingano, Kamsá, Corregaje, Tatuyo (Vaupes) e Carijona. Pacho Piaguaje foi eleito membro do Grande Conselho da UMIYAC e aparece com vestimentas completas de xamã em duas fotos do livro. Ele é citado como "o maior e mais respeitado dos taitas Siona" (UMIYAC, 1999, p. 135). Três outros homens mais jovens que eu conhecia bem também haviam se tornado taitas e participaram desse encontro: Felinto, o filho de Pacho, seu sobrinho Hermógenes (filho de Luciano) e Juan Yaiguaje, um Siona casado com a neta de Ricardo. Fiquei surpresa e feliz ao ver esses homens como taitas. Nos anos 1970, quando eu os conheci, ninguém imaginaria que futuramente poderiam se interessar pelo xamanismo. 


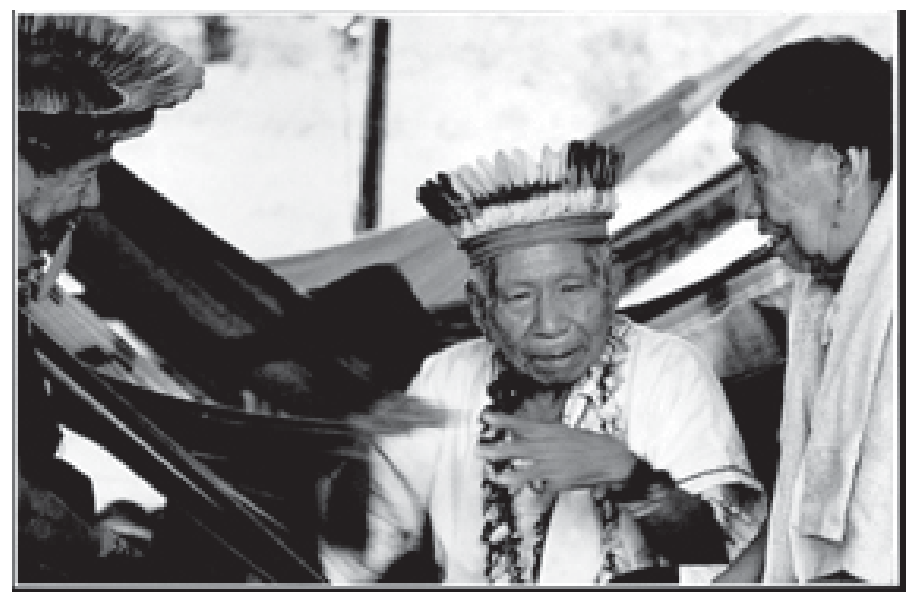

Figura 3: Taita Pacho no Encuentro de Taitas em la Amazonia Colombiana Fonte: UMIYAC, 1999, p. 105 (reproduzida com autorização).

Embora não tenha estado presente no encontro, vendo a publicação com suas fotos, as afirmações de taitas e a Declaração do Encontro de taitas, é evidente que a ideologia da União é uma expressão da resposta indígena às visões globalizadas sobre o xamanismo, concebido como uma prática espiritual com um conhecimento primordial especial que honra e protege o meio ambiente. Durante o tempo de Ricardo, os encontros entre xamãs eram caracterizados por desconfiança, medo de possíveis ataques de feitiçaria pelos xamãs presentes, e posteriormente foram frequentemente seguidos por acusações, tais como aquelas gravadas por Jackson (1995). A UMIYAC foi formada através do espírito de colaboração com a intenção de defender o direito indígena de praticar a medicina tradicional. A Declaração da UMIYAC, elaborada durante o Encontro, condena os não indígenas que promovem o turismo psicodélico e o patenteamento do yajé e de outras plantas indígenas. Seu código de ética declara que o grupo tem a intenção de regular o uso autêntico do yajé e os verdadeiros praticantes da medicina indígena, distinguindo-os dos charlatões. Ela também condena o abuso do álcool e o uso de aguardiente durante rituais de yajé. Fiquei sabendo que Pacho saiu do UMIYAC em poucos anos por conflitos ligados, em parte, por seus hábitos de beber (Caicedo Fernández, em comunicação pessoal). 


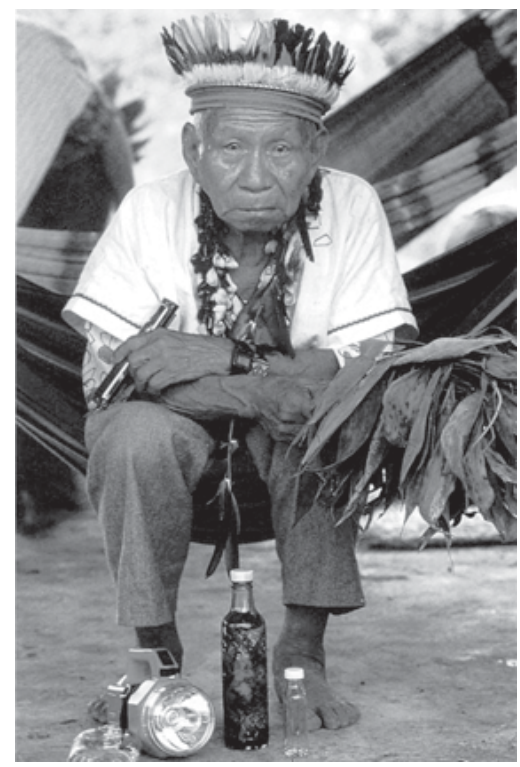

Figura 4: Taita Pacho após uma sessão de cura Fonte: UMIYAC, 1999, p. 31 (reproduzida com autorização).

Em 2001, a União recebeu a Distinção Ambiental Máxima do Presidente da Colômbia devido aos seus esforços em manter e preservar a biodiversidade da floresta (Colômbia, 2001). Como Albert (2002), Carneiro da Cunha (1998) e Conklin $(1997,2002)$ observaram entre os indígenas brasileiros, o diálogo intercultural com esses xamãs do Putumayo reflete os interesses ambientais de organizações não governamentais internacionais.

Pacho continuou sendo um xamã muito conhecido entre intelectuais não indígenas até sua morte, no início de 2007, viajando entre a selva e as cidades e treinando alguns para se tornarem xamãs, e, desde então, seus filhos vêm continuando com essa mediação. Embora a cosmologia xamânica continue a ser manifestada na vida cotidiana dos Siona através do discurso e dos rituais ligados às enfermidades graves ou a acidentes mortais, o status de Pacho como "o maior e mais respeitado xamã Siona" é mais um reflexo da modernidade - ou da pós-modernidade, se quisermos usar esse termo - e de forças que estão do lado de fora da comunidade nativa. Minha pesquisa de campo limitada, alimentada pelas observações de 
outros que passaram pela área, mostra que poucos Siona bebiam yajé com ele nos anos 1980 e 1990 e que ele não preenchia o papel tradicional de cacique-curaca. Ele não tinha passado pelo processo de aprendizado xamânico tradicional dos Siona, o caminho legítimo para o reconhecimento da comunidade. Ele bebia grandes quantidades de aguardiente, tradicionalmente proibida para os xamãs Siona, embora nem todos os grupos da região percebam isso como contrário às práticas xamânicas, especialmente os inganos das terras baixas e os curacas sibundoy. O abandono das práticas de reclusão para as mulheres menstruadas e grávidas não ameaçava seu corpo, como acontecia com Ricardo.

Porém, experiências com ele relatadas por outros, a autobiografia de Weiskopf e a pesquisa recente de Caicedo Fernández (2007), antropóloga que estuda as redes xamânicas entre os taitas da selva e os intelectuais urbanos, convenceram-me de que Pacho levava os participantes dos rituais a verem as pintas características do xamanismo Siona. O consumo de yajé liderado pelos taitas nos centros urbanos tem aumentado e se diversificado. Concomitantemente, a aprendizagem xamânica que estava abandonada pelos índios jovens na década de 1970 hoje é revitalizada, resultando na formação de novas gerações de yajeceros. Para Caicedo Fernández (2009), que entrevistou os discípulos não indígenas de Pacho, seu caso é paradigmático dos processos de urbanização e elitização do consumo ritual de yajé na Colômbia.

Vários fatores históricos e globais combinados contribuíram para estimular a revitalização do xamanismo Siona: a cultura popular colombiana, que durante séculos procurou as curas xamânicas; o mercado global para o xamanismo; e as visitas de vários forasteiros motivados pelo renovado interesse no xamanismo a partir dos anos 1950 - o beatnik William Burroughs, o etnobotânico Richard Schultes, o médico holístico da Nova Era Andrew Weil, antropólogos, jornalistas, ativistas indígenas e psiconautos. Poderíamos concluir que, no contexto da modernidade, Pacho tornou-se um xamã tradicional sem necessariamente ter a aprovação tradicional da comunidade. Refletindo sobre as memórias das minhas pesquisas ao longo dos anos, 
tentei mostrar que, em parte, isso se deve ao próprio Pacho, como um indivíduo único e particular.

Esta narrativa também tem o objetivo de dialogar com a teoria antropológica e os escritos etnográficos que não estão diretamente ligados ao tema do xamanismo, pois ela nos força a levar em consideração questões antropológicas mais amplas. Minha reflexão sobre a vida de Pacho demonstra minhas limitações pessoais e a óbvia fragmentação da abordagem antropológica. Ela também mostra as inadequações da abordagem normativa da cultura que era característica no período da minha primeira pesquisa de campo e reflete as questões, os dilemas e as mudanças na antropologia durante os últimos quarenta anos. De fato, outros conceitos antropológicos seriam mais adequados para entender as transformações no xamanismo nas últimas quatro décadas, tais como dialogicidade ou intertextualidade, para chamar atenção às múltiplas vozes que contribuem para a construção das práticas xamânicas atuais e a compreensão melhor da relação entre o local e o global. Procuramos substituir esse conceito por noções como práxis, poder, processos identitários, recriação da tradição e emergência dialógica. Porém, enquanto os antropólogos procuram substituir o conceito, a noção de cultura tornou-se importante para os grupos étnicos que a defendem como essencial para sua identidade (Warren e Jackson, 2002).

\section{Notas}

${ }^{1}$ Este texto é a revisão do artigo Shamans and Shamanism: Reflections on Anthropological Dilemmas of Modernity, da Revista Vibrant, v. 4, n. 2, p. 27-48. Agradeço à Isabel Santa de Rose pela tradução.

${ }^{2}$ Fiquei tão impressionada com a fala dele que não consigo me lembrar de quem eram os outros participantes.

${ }^{3}$ Participei de vários simpósios internacionais nos anos 1980, nos quais os critérios essenciais para identificar os xamãs eram discutidos e os cultos de origem africana eram excluídos porque não tinham o contexto histórico necessário e porque suas experiências extáticas eram caracterizadas pela possessão, e não pelo voo xamânico.

${ }^{4} \mathrm{O}$ yajé também é amplamente denominado como ayahuasca. Embora em publicações anteriores tenha usado a ortografia yagé, estou aqui seguindo a ortografia de Uribe (2002), que argumenta que yajé é a representação mais correta em espanhol.

${ }^{5}$ Entre os homens da comunidade, seu irmão era o único outro que usava a cusma, mas não usava a vestimenta cerimonial. Algumas mulheres mais velhas usavam a blusa

\section{ILHA}

volume 11 - número 2 
tradicional introduzida pelos missionários, mas os jovens tentavam seguir as tendências populares nas maneiras de se vestirem (Langdon, 1979b).

${ }^{6}$ Guerrero (1991) escreveu sobre Taita Martin e seu ritual de yajé.

${ }^{7}$ Em sua autobiografia, Weiskopf observa que não foi muito bem-vindo ou compreendido pelos Siona, que perguntavam, segundo ele, "o que este gringo está fazendo aqui?" (2005, p. 68).

${ }^{8}$ A esposa, mulher que ensinou artesanato para os Siona e que, de fato, é escocesa, publicou um diário sobre suas viagens pelo Rio Putumayo (Meikle, 2003).

${ }^{9}$ Embora Jimmy Weiskopf (2005) tente mascarar a identidade de Pacho na autobiografia de suas experiências com o yajé, como Pacho era uma figura pública que não tinha nenhuma pretensão de trabalhar secretamente, decidi não trabalhar com nomes fictícios.

${ }^{10} \mathrm{Na}$ língua Siona, taita significa pai e é um termo geralmente usado para designar pessoas mais velhas, dotadas ou não de poderes xamânicos.

\section{Referências}

ALBERT, Bruce. Ouro canibal e a queda do céu: uma crítica xamânica da economia política da natureza. In: ALBERT, Bruce; RAMOS, Alcida Rita (Org. ). Pacificando o branco: cosmologias do contato no norte-amazônico. São Paulo: Ed. UNESP/Imprensa Oficial do Estado, 2002. p. 239-276.

BRUNELLI, Gilio. Do xamanismo aos xamãs: estratégias tupi-mondé frente à sociedade envolvente. In: LANGDON, Esther Jean Matteson (Org.).

Xamanismo no Brasil: novas perspectivas. Florianópolis: Ed. UFSC, 1996. p. 233-266.

BURROUGHS, William S.; GINSBERG, Allen. The Yagé Letters. San Francisco: City Lights Books, 1963.

CAICEDO FERNÁNDEZ, Alhena. Neochamanismos y modernidad: lecturas sobre la emancipación. Revista Nómadas, Bogotá: Iesco-Universidad Central, n. 26, p. 114-147, 2007. Disponível em: <www.ucentral.edu.co/NOMADAS/.../ 9-neochamanismos\%20alhena.pdf>. Acesso em: 10 ago. 2010.

. Neochamanismo yajecero en contextos urbanos colombianos. In: CONGRESS OF AMERICANISTS, 2009, Mexico City.

CARNEIRO DA CUNHA, Manuela. Pontos de vista sobre a Floresta Amazônica: xamanismo e tradução. Mana, Rio de Janeiro, v. 4, n. 1, p. 7-22, 1998.

CASTANEDA, Carlos Carlos. The Teachings of Don Juan: A Yaqui Way of Knowledge. Berkeley: University of California Press, 1968.

CHAVES, Margarita. Identidade y representación entre indígenas y colonos de la Amazonia colombiana. In: SOTOMAYOR, María Lúcia (Org.). Modernidade, identidade y desarrollo: construcción de sociedad y re-creación cultural en contextos de modernización. Bogotá: Instituto Colombiano de Antropología (Colciencias), 1998. p. 273-287.

\section{ILHA}


COLOMBIA. Ministerio del Medio Ambiente. Un reconocimiento hecho a través del Ministerio del Medio Ambiente, al esfuerzo individual y colectivo en pro del desarrollo sostenible. Comunicados Septiembre 2001. Disponível em: $<$ htpp://www.minambiente.gov.co/html/prensa/comunicados > . Acesso em: 10 maio 2007.

CONKLIN, Beth A. Body Paint, Feathers, and Videos: Aesthetics and Authenticity in Amazonian Activism. American Ethnologist, Washington, v. 24, n. 4, p. 711-737, 1997.

. Shamans versus Pirates in the Amazonian Treasure Chest. American Anthropologist, Washington, v. 104, n. 4, p. 1050-1061, 2002.

DOBKIN DE RIOS, Marlene. Amazon Healer: The Life and Times of an Urban Shaman. Bridgeport: Prison Press, 1992. Dist. by Avery Pub.

DUMONT, Louis. Essays on Individualism: Modern Ideology in Anthropological Perspective. Chicago: University of Chicago Press, 1986.

GEERTZ, Clifford. Religion as a Cultural System. In: BANTON, Michael (Org.). Anthropological Approaches to the Study of Religion. London: Tavistock Publications, 1966. p. 1-46.

GREENE, Shane. The Shaman's Needle: Development, Shamanic Agency, and Intermedicality in Aguaruna Lands, Peru. American Ethnologist, Washington, v. 25, n. 4, p. 634-658, 1998.

GUERRERO, Horacio. Pinta, pinta, cura, cura, gente. In: AMODIO, Emanuele; JUNCOSO, José E. (Org.). Espiritus aliados: chamanismo y curación en los pueblos índios de sudamérica. Quito: Abya-Yala, 1991. p. 209-253.

GUPTA, Akhil; FERGUSON, James. Culture, Power, Place. Durham: Duke University Press, 2001.

HAMAYON, Roberte N. Shamanism: Symbolic System, Human Capability and Western Ideology. In: FRANCFORT, Henri-Paul; HAMAYON, Roberte N. (Orgs.). The Concept of Shamanism: uses and abuses. Budapest: Adadémiai Kiado, 2001.p. 1-29.

HARNER, Michael. The Role of Hallucinogenic Plants in European Witchcraft. In: HARNER, Michael (Org.). Hallucinogens and Shamanism. New York: Oxford University Press, 1973. p. 125-150.

JACKSON, Jean Elizabeth. Preserving Indian Culture: Shaman Schools and Ethno-Education in the Vaupés, Colômbia. Cultural Anthropology, Washington, v. 10, n. 3, p. 301-329, 1995.

JORALEMON, Donald. The Performing Patient in Ritual Healing. Social Science and Medicine, Amsterdam, v. 23, n. 9, p. 841-885, 1986. 
. The Selling of the Shaman and the Problem of Informant Legitimacy. Journal of Anthropological Research, Albuquerque, New Mexico, v. 46, n. 2, p. 105-118, 1990.

; SHARON, Douglas. Sorcery and Shamanism: Curanderos and Clients in Northern Peru. Salt Lake City: University of Utah Press, 1993.

LANGDON, Esther Jean. Yagé among the Siona: Cultural Patterns and Visions. In: BROWMAN, David L.; SCHWARZ, Ronald A. (Org.). Spirits, Shamans and Stars: Perspectives from South America. The Hague: Mouton Publishers, 1979a. p. 63-82.

. Siona Clothing and Adornment, or You are What you Wear. In: CORDWELL, Justine M.; SCHWARZ, Ronald A. (Org.). The Fabric of Culture: Anthropology of Clothing and Adornment. J. The Hague: Mouton Publishers, 1979b. p. 297-312.

. Social Bases for Trading of Visions and Spiritual Knowledge in the Colombian and Ecuadorian Montaña. In: NETWORKS OF THE PAST, 1981, Canadá: The Archaeological Association of the University of Calgary. Proceedings... Canadá, 1981.p. 101-116.

. La historia de la conquista de acuerdo a los indios siona del Putumayo. In: PINEDA CAMACHO, Roberto; ALZATE ANGEL, Beatriz (Org.). Los meandros de la historia em Amazônia. Quito: Ediciones Abya-Yala, 1990. p. 13-41.

. Poder y autoridad en el proceso político siona: desarrollo y muerte del shaman. In: EHRENREICH, Jeffrey (Org.). Antropologia política en el Ecuador. Quito: Ediciones Abya-Yala, 1991a. p. 161-188.

. Interethnic Processes Affecting the Survival of Shamans: A Comparative Analysis. In: PINZÓN CASTAÑO, Carlos Ernesto; SUÁREZ P., Rosa (Org.). A otra America en construcción: medicinas tradicionales, religiones populares. Bogotá: Instituto Colombiano de Antropología/Instituto Colombiano de Cultura, 1991b. p. 44-65.

. Introduction. In: LANGDON, Esther Jean Matteson; BAER, Gerhard (Org.). Portals of Power: Shamanism in South America. New México: University of New Mexico Press, 1992. p. 1-21.

. A morte e corpo dos xamãs nas narrativas Siona. Revista de Antropologia da USP, São Paulo, v. 38, n. 2, p. 107-149, 1995.

. Introdução. In: LANGDON, Esther Jean Matteson (Org.). Xamanismo no Brasil: novas perspectivas. Florianópolis: Ed. UFSC, 1996. p. 1-25.

. Representações do poder xamanístico nas narrativas dos sonhos Siona. Il ha: Revista de Antropologia, Florianópolis: Ed. UFSC, v. l, n. 1, p. 35-56, 1999. 
. A doença como experiência: o papel da narrativa na construção sociocultural da doença. Etnográfica: Revista do Centro de Estudos de Antropologia Social, Lisboa, v. 2, p. 241-260, 2001.

. A tradição narrativa e aprendizagem com yagé (ayahuasca) entre os índios Siona da Colômbia". In: LABATE, Beatriz Caiuby; ARAÚJO, Valdimyr (Org. ). O uso ritual da ayahuasca. Campinas: FAPESP/Mercado de Letras, 2002. p. 67-94.

. Shamanismo y sueños: subjetividad y representaciones de sí mismo en narrativas de sueños siona. In: CIPOLLETI, María Susana (Org.). Los mundos de abajo y los mundos de arriba: individuos y sociedad en las tierras bajas y los Andes. Homenaje a Gerhard Baer. Quito: Ediciones Abya-Yala. 2004. p. 26-51.

LUNA, Luis Eduardo; AMARINGO, Pablo. Ayahuasca Visions: The Religious Imaginery of Pablo Amaringo. Berkeley: North Atlantic Books, 1991.

MALLOL DE RECASENS, Maria Rosa. Cuatro representaciones de las imagenes alucinatorias originadas por la toma del yagé. Revista Colombiana de Folclor, Bogotá, v. III, n. 8, p. 59-79, 1963.

; RECASENS T., José. de. Contribución al conocimiento del caciquecuraca entre los Siona. Revista Colombiana de Antropologia, Bogotá, v. 13, p. 91$145,1964 / 1965$.

MEIKLE, Valerie. To the Heart of the Amazon: Journey of a Lifetime. Dublin: Apollo Print Solutions, 2003.

RAMÍREZ DE JARA, María Clemencia. The Politics of Identity and Cultural Difference in the Colombian Amazon: Claiming Indigenous Rights in the Putumayo Region. In: MAYBURY-LEWIS, David (Org.). The Politics of Ethnicity: Indigenous Peoples in Latin American States. Cambridge: Harvard University Press, 2002. p. 135-166.

RAMÍREZ DE JARA, María Clemencia; PINZÓN CASTAÑO, Carlos Ernesto. Sibundoy Shamaism and Popular Culture in Colombia. In: LANGDON, Esther Jean Matteson; BAER, Gerhard (Org.). Portals of Power: Shamanism in South America. Albuquerque: University of New Mexico Press, 1992. p. 287-303.

ROBINSON, Scott S. Hacia una comprensión del shamanismo cofán. Quito: Ediciones Abya-Yala, 1996.

SEEGER, Anthony; DA MATTA, Roberto; VIVEIROS DE CASTRO, Eduardo. A construção da pessoa nas sociedades indígenas brasileiras. In: OLIVEIRA FILHO, João Pacheco de (Org. ). Sociedades indígenas e indigenismo no Brasil. Rio de Janeiro: Ed. UFRJ/Marco Zero, 1987. p. 11-30.

TAUSSIG, Michael. Shamanism, Colonialism, and the Wild Man: A Study in Terror and Healing. Chicago: University of Chicago Press, 1987. 
UMIYAC. Unión de Medicos Indígenas Yageceros de Colombia. Encuentro de Taitas en la Amazonía Colombiana. Santafé de Bogotá, Colômbia: UMIYAC, 1999. . Codigo de ética médica. 2005. Disponível em: < http://rojointenso.net/ foros/index.php? showtopic $=3788$ mode $=$ threaded $>$. Acesso em: $28 \mathrm{de}$ março de 2010.

URIBE, Carlos Alberto. El yajé como sistema emergente: discusiones y cotroversias. Documentos CESO \#33. Centro de Estudos Socioculturales e Internacionales. Bogotá: Universidade de los Andes. 2002.

VIDAL, Silvia M. El chamanismo de los arawakos del Rio Negro: su influencia en la politica local y regional en el Amazonas de Venezuela. Brasília: UnB, 2002. 20 p. (Série Antropologia, 313).

VIDAL, Silvia M.; WHITEHEAD, Neil L. Dark Shamans and the Shamanic State: Sorcery and Witchcraft as Political Process in Guyana and the Venezuelan Amazon. In: WHITEHEAD, Neil L.; WRIGHT, Robin (Org.). In Darkness and Secrecy: The Anthropology of Assault Sorcery and Witchcraft in Amazonia. Durham: Duke University Press, 2002. p. 51-80.

WARREN, Kay B.; JACKSON, Jean Elizabeth. Introduction. In: WARREN, Kay. B.; JACKSON, Jean Elizabeth (Org). Indigenous Movements, Self-Representation and the State in Latin America. Austin: University of Texas Press, 2002. p. 1-46.

WEIL, Andrew Thomas. The Natural Mind: A New Way of Looking at Drugs and the Higher Consciousness. Boston: Houghton-Mifflin, 1972.

WEISKOPF, Jimmy. Yajé: The New Purgatory - Encounters with Ayahuasca. Bogotá: Villegas Editores, 2005.

WHEELER, Alva. Grammatical Structure in Siona Discourse. Lingua, v. 19, p. 66-77, 1967.

. 1970. Grammar of the Siona Language, Colombia, South America. Tese (Doutorado) - Universidade da California, Berkeley, 1970.

WHITEHEAD, Neil L. Dark Shamans: Kanaima and the poetics of violent death. Durham: Duke University Press, 2002.

Recebido em: 15/07/2010

Aceite em: 20/08/2010

\section{ILHA}

volume 11 - número 2 